superseded by Einstein's theories, so alternative medical paradigms may also still be useful in appropriate situations.

S R BUCKNALI

Glasgow G62 8NL

1 Kuhn T. The structure of scientific revolutions. Chicago: University of Chicago Press, 1962.

\section{Bacterial contamination of home nebulisers}

SIR,-Local experience may be of some relevance to the correspondence about bacterial contamination of home nebulisers (30 October, p 812; 14 November, p 1281).

Atomiser units of five "cool mist tents" on a paediatric ward were contaminated with an oxidase positive, Gram negative organism producing yellow colonies on the blood agar after 48 hours' incubation. Decontamination of the machines with an autoclave with a pasteurisation cycle was soon followed by recontamination by the organism, which was identified as Pseudomonas paucimobilis. Staff had been instructed to use only sterile wate when filling the atomiser reservoirs and to store the machines in a dry state. Questioning revealed the practice of "washing out" the units with tap water before dry storage. Bacterial examination of the ward taps revealed heavy colonisation by $P$ paucimobilis. The persistence of contamination despite prolonged dry storage was explained by laboratory studies in which dried smears made from thick suspensions of $P$ paucimobilis showed viability for up to $\mathbf{5 0}$ days at room temperature. During the period of study there were no clinica isolates of $P$ paucimobilis from patients, though evidence of pathogenic potential exists. ${ }^{23}$

This experience prompts me to caution against advising patients to use unboiled tap water when "washing" nebulisers and to note that although desirable, dry storage of such equipment is not always an infallible means of preventing contamination.

B A S DALE

Dumfries and Galloway Royal Infirmary,

Dumfries DG1 4AP

1 Dale BAS, Williams J. Pseudomonas paucimobilis contamination of cool mist tents on a paediatric ward. $\mathcal{F}$ Hosp Infect 1986;7:189-92.

2 Southern PM, Kutscher AE. Pseudomonas paucimobilis bacteraemia. F Clin Microbiol 1981;13:1070-3.

3 Hajiroussou V, Holmes B, Bullas J, Pinning CA. Meningitis caused by Pseudomonas paucimobilis. J Clin Pathol 1979;32. 953-5.

The blood transfusion service and zidovudine treatment for AIDS

SIR,-There has been recent correspondence about a shortage of blood for transfusion in the South West Thames region (Drs J E W Van de Pette and Janet A Shirley, and Dr K Ll Rogers (24 October, p 1061, 1062)). We should like to draw attention to an increasingly large group of patients in this region with a transfusion requirement which might be difficult to meet given the decline in blood donations.

St Stephen's Hospital cares for many patients with human immunodeficiency virus (HIV) infection, many of whom need blood transfusion. We have noticed an increase during 1987 in the number of HIV positive patients transfused, this being due partly to the ever expanding numbers of patients ill with the acquired immune deficiency syndrome (AIDS) but also to the introduction of the antiviral agent zidovudine into the management of HIV disease. This agent induces severe anaemia in about a quarter of recipients. ${ }^{1}$

During the 10 months January to October 1987
53 HIV positive patients were transfused. The number of transfusions was 94 , and 314 units of blood were given. Of the 53 patients transfused, 31 were receiving zidovudine. These 31 patients had 68 transfusions altogether to a total of 213 units of blood; 23 required transfusion more than once (up to 6 times).

In comparison, during January to October 1986 , when there were fewer patients with AIDS and no zidovudine, 46 transfusions were given to 25 patients ( 8 had more than one transfusion); the total number of blood units used was 158 . These figures are distorted by the fact that one patient, who had acute leukaemia, required 13 transfusions (total 43 units). Excluding this patient would have made the increase in blood use during 1987 more apparent. Even including this patient it is obvious that we have at least doubled our consumption of blood from 1986 to 1987.

The heavy financial costs of managing patients with AIDS and of using zidovudine are well known. Our blood transfusion figures indicate that money is not the only resource of importance in the management of HIV infected individuals. The South London Transfusion Centre is already badly stretched to provide blood for all patients within the region. Escalating use of zidovudine and increasing numbers of sick patients with AIDS can only increase the demand for a commodity which is perilously scarce. Unless the number of blood donors increases to meet current demands it migh even be necessary to restrict the use of zidovudine.

Christine Costello NAHEED MIR JOHN LUCKIT

Department of Haematology, St Stephen's Hospital, Chelsea, London SW10 9TH

1 Richman DD. The toxicity of azidothymidine in the treatment of patients with AIDS and AIDS-related complex. $N E n g l F ~ M e d$ 1987;317:192-7.

\section{OKT3 and cerebral oedema}

SIR,-The recent paper by Dr P A Rowe and colleagues (31 October, p 1099) highlighted the problem of pulmonary oedema induced by monoclonal antibody against the $\mathrm{CD} 3$ receptor of T lymphocytes (OKT3) in patients with acute allograft rejection. Cerebral oedema has not been previously described. We report on a patient who developed this complication after receiving OKT3.

A 34 year old highly sensitised woman received her second cadaveric renal transplant through the United Kingdom Transplant SOS scheme. Initial immunosuppression was with prednisolone, cyclosporin, and azathioprine. At six days she had an episode of acute rejection proved by biopsy, which was treated with OKT3 although she was more than 3\% above her dialysis weight. Despite intravenous frusemide, within 30 minutes she developed pulmonary oedema, which was relieved by ultrafiltration. Next morning she had headache, photophobia, nausea, and neck stiffness. She was febrile and again had pulmonary oedema.

Lumbar puncture produced cerebrospinal fluid at a pressure of $34.5 \mathrm{~cm} \mathrm{H} \mathrm{H}_{2} \mathrm{O}$ with 53 polymorphs/ $\mu l$. No organisms were seen. Antibiotics were started and ultrafiltration resumed with immediate improvement: within 18 hours she was completely better. Because of the results of microscopy of the cerebrospinal fluid and negative cultures the antibiotics were stopped after five days.

The high cerebrospinal fluid pressure with rapid clinical improvement after fluid removal suggests that our patient had cerebral oedema and no bacterial meningitis. Headache is a common side effect of OKT3 but cerebral oedema has not been described.

D M THOMAS

A J NichOLLS

T G FEEST

H RIAD

Royal Devon and Exeter Hospital (Wonford)

Exeter EX2 5DW

Treatment of primary biliary cirrhosis

SIR,-DrN DC Finlayson paints a gloomy picture for patients and physicians alike and in our opinion is too nihilistic (10 October, $p$ 867).

Our unit's interest in specific treatments for primary biliary cirrhosis ${ }^{1}$ began with the use of corticosteroids in 1958 and has continued with the first controlled trial of colchicine treatment, which started in 1979. ${ }^{2}$ While we agree with Dr Finlayson that problems exist in the design, execution, and interpretation of clinical trials in primary biliary cirrhosis, some of these are potentially soluble. Our own approach has been to use a "pair matched" study design, which ensures excellent comparability of patients in treatment and placebo groups and avoids the need for statistical recalculation as used in the last azathioprine trial. ${ }^{3}$

While the possibility of a small beneficial effect of azathioprine cannot be discounted, to our knowledge all clinical trials of this drug in primary biliary cirrhosis have now been abandoned. The results of continuing trials of corticosteroids and cyclosporin are awaited and it is clear that controlled studies of bile acid treatment are indicated. Of the treatments currently available, however, colchicine, which Dr Finlayson dismisses in one sentence, appears the most promising. Three independent controlled trials have now shown significant biochemical improvements with this drug and one has shown improved survival. ${ }^{246}$ Nevertheless, larger longer term studies are required to establish the full potential of this drug in the treatment of primary biliary cirrhosis.

Future drug trials in primary biliary cirrhosis should be large enough to exclude type II error and patients will require follow up for many years, preferably using sequential dynamic tests of liver function and serum markers of fibrogenesis such as procollagen III peptide, to establish new therapeutic end points. Drug trials should include asymptomatic patients since many of these have portal hypertension, ${ }^{7}$ active fibrogenesis, established cirrhosis, and decreased survival. ${ }^{8}$

Progress has been made in both the symptomatic and specific treatment of primary biliary cirrhosis and in the assessment for and timing of liver transplantation. ${ }^{39}$ Further progress now depends on medical practitioners referring patients with primary biliary cirrhosis to centres willing to undertake well designed, large scale, and long term studies of drug treatments in this disease.

C BABBS A SMITH $T$ W WARNES

Liver Clinic,

Manchester Royal Infirmary

Manchester M13 9WL

1 Warnes TW. Treatment of primary biliary cirrhosis. Seminars on Liver Disease 1985;5:228-40.

2 Warnes TW, Smith A, Haboubi NY, Johnson PJ, Hunt I. A controlled trial of colchicine in primary biliary cirrhosis. Hepatology 1984;4:1022.

3 Christensen E, Neuberger J, Crowe J, et al. Beneficial effect of azathioprine and prediction of prognosis in primary biliary cirrhosis. Gastroenterology 1985;89:1084-91.

4 Warnes TW, Smith A, Lee FI, Haboubi NY, Johnson PJ, Hunt L. A controlled trial of colchicine in primary biliary cirrhosis. f Hepatol 1987;5:1-7.

Kaplan MM, Alling DW, Zimmerman HJ, et al. A prospective

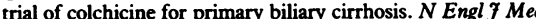
$1986 ; 315: 1448-54$

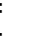


6 Bodenheimer H, Schaffner F, Pezzullo J. Colchicine therapy in primary biliary cirrhosis. Hepatology 1986;6:1172.

7 Warnes TW, Smith A, Haboubi NY, Cope V, Vales P. Porta hypertension in primary biliary cirrhosis-an early assault on the sinusoids. Hepatology, 1984;4:751.

8 Balasubramaniam K, Grambsch PM, Weisner RH, Lindor KD Dickson ER. Asymptomatic primary biliary cirrhosis (PBC) Dickson ER. Asymptomatic primary biliary cirrhosis (PBC):
patients have diminished survival. Hepatology 1987;5:1025.

9 Neuberger J, Altman D, Christensen E, Tygstrup N, Williams R. Use of a prognostic index in evaluation of liver transplanta tion in primary biliary cirrhosis. Transplantation 1986;41 713-6.

\section{Self injury and mental handicap}

SIR,-Like suicide, self injury is a form of self mutilation and is not always a form of attention seeking due to boredom, as Dr Brian Kirman assumes (31 October, p 1086).

Suicide and self mutilation are often forms of aggression turned inwards and associated with aggression to others. This is particularly true of the mentally retarded. Control of aggression is difficult but notoriously so in those severely retarded. From 1969 onwards there have been several reports on the usefulness of lithium in patients exhibiting aggression. The patients included groups of delinquents, psychotics, and the mentally handicapped. The larger studies indicate a positive response in some $70-75 \%$ of cases. ${ }^{2}$

These figures were confirmed in the first published multicentre double blind trial of lithium in mentally handicapped patients, published last May. ${ }^{3}$ Until the survey quoted by Dr Kirman ${ }^{4}$ is published it is not possible to say whether the authors were aware of this but it seems unlikely.

Lithium is not necessarily a cure and is usually given only when all other methods have failed, although a plea for its earlier use in these patients was made recently. ${ }^{5}$ It seems helpful in relieving aggression, including self mutilation, in these patients, which distresses them, their relatives, and staff. The grave shortages of staff trained in behavioural techniques may to some extent be relieved if this element is used with effect. The patient may become more receptive to this type of treatment.

P G DALE

Mental Handicap Services,

Goldcrest Hospital,

Sarisbury Green,

Southampton SO3 6ZD

1 Simpson GM. Lithium therapy in aggressive mentally subnormal patients. Br f Psychiatry 1981;138:438.

2 Wickham EA, Reed JV. Lithium for the control of aggressive and self-mutilating behaviour. Intemational Psychopharmacology 1987;2:181-90.

3 Craft M, Ismail IA, Krishnamurti D, et al. Lithium in the treatment of aggression in mentally handicapped patients. $\mathrm{Br} \mathcal{J}$ Psychiatry 1987;150:685-9.

4 Oliver C, Murphy GH, Corbett JA. Self-injurious behaviour in people with mental handicap: a total population study. $\mathcal{F}$ Ment Defic Res (in press)

5 Dale PG. Lithium in the treatment of aggression in mentally handicapped patients. Brf Psychiatry 1987;151:413.

\section{Potassium citrate mixture: Soothing but not} harmless?

SIR,-Drs J E Elizabeth and N J Carter (17 October, p 993) have presented data suggesting that therapeutic or supranormal doses of potassium citrate mixture can cause life threatening hyperkalaemia. Unfortunately their data are incomplete and therefore they may have drawn untenable conclusions.

No reliable estimate of glomerular filtration rate is given, but, more importantly, the authors failed to measure any urinary variables. In health urinary potassium ranges from 30 to $100 \mu \mathrm{mol} /$ day depending on potassium intake ${ }^{1}$ and may rise to twice this figure if progressive potassium loading is undertaken in people with normal kidneys. Assuming tubular patency, urinary potassium is determined by the quantities of potassium secreted by distal converted tubules and collecting ducts. ${ }^{2}$ Drs Elizabeth and Carter have assumed that in their two patients the rate of ingestion of potassium was greater than the rate of potassium excretion. Both patients had urinary tract infections, the localisation of which was not stated, and the authors assume that "renal function was normal." They do not provide evidence for this supposition. One well recognised feature of acute pyelonephritis is suppression of urine formation due to intrarenal oedema causing an obstructive uropathy which is accompanied by an inability to excrete potassium. This, I suggest, is the most likely cause of the reported hyperkalaemia. The same error was made by the two authors of the two apparently comparable cases cited by Drs Elizabeth and Carter. ${ }^{34}$

Finally, I am surprised that potassium citrate $B P$ is still used. It is a foul tasting solution indicated only if a renal tract infection is to be treated with aminoglycoside. ${ }^{5}$ Sodium bicarbonate is better and more acceptable in this respect.

Renal Unit,
St Mary's Hospital, w2 INY

ROGER GABRIEL

1 Schuck O. Examination of kidney function. Boston: Martinus Nijhoff. 1984:170. (Developments in Nephrology Vol 4.) 2 de Wardener HE. The kidney. Sth ed. Edinburgh: Churchill Livingstone, 1985:99.

3 Browning JJ, Channer KS. Hyperkalaemic cardiac arrhythmia caused by potassium citrate mixture. BrMed f 1981;283:1366. 4 Wilson RG, Farndon JR. Hyperkalaemic cardiac arrhythmia Wilson RG, Farndon JR. Hyperkalaemic cardiac arrhythmia
caused by potassium citrate mixture. $\mathrm{Br} M e d \mathcal{f} 1982 ; 285$ : 197-8.

5 Gabriel R. Postgraduate nephrology. 3rd ed. London: Butterworths, 1985:72.

Micrometastases in bone marrow in patients with breast cancer

SIR,-The paper by Dr Janine Mansi and others ( 31 October, p 1093) is essentially on the prediction of the development of symptomatic metastases in breast cancer. Their conclusion that their test epithelial membrane antibody staining of bone marrow is "a useful predictor of early relapse" is not even justified by their own figures. This factor did not emerge as a strong variable and when other prognostic variables were taken into consideration was completely eliminated.

The conclusion from their study must be that the prognostic variables of grade and stage are better at predicting the subsequent development of symptomatic metastases than is their test. Furthermore, their test is difficult to undertake requiring marrow biopsy at eight different sites in each patient. Measurement of grade and stage are easily undertaken and are in fact routine in many centres. Several years ago we showed that combining these factors gives an excellent index of prognosis ${ }^{1}$ and we have recently confirmed the value of this index prospectively.

As to the accuracy of the bone marrow test, it is noteworthy that of 307 patients, 84 had stage III or IV disease, in whom we may assume that metastases were certainly present. Their test gave a sensitivity of only $43 \%$.

R W BLAMEY

J F R ROBERTSON

A P LOCKER

City Hospital,

Nottingham NGS IPB

1 Haybittle JL, Blamey RW, Elston CW, et al. A prognostic index in primary breast cancer. Brf Cancer 1982;45:361-6.

2 Todd JH, Dowle C, Williams MR, et al. Confirmation of prognostic index in primary breast cancer. $B r \mathcal{F}$ Cancer 1987;
56:489-92.

\section{Disciplining doctors}

SIR,-I would echo Dr David Roy's comments (7 November, $p$ 1190) that as a system for disciplining doctors the $\mathrm{HM}(61) 112$ procedure is bad for the patients (who are deprived of the skills of the suspended doctor), bad for the National Health Service (over $£ 30 \mathrm{~m}$ spent on these procedures since this government first came into office), and bad for the doctors.

Chief among the problems is the time it takes to resolve a case. It is absurd that one doctor had to go to the High Court one year after his suspension to find out what he was accused of. Equally it is monstrous that a doctor can be suspended for years only to be told eventually that all accusations against him are withdrawn. The stress that such a prolonged suspension creates is destructive to both the doctor and his family, and no amount of financial settlement can make adequate recompense.

The central difficulty is that district medical officers, who in teaching districts are responsible for the initial suspensions, have little or no training in deciding the professional competence of a highly trained consultant or how to assess whether there is a prima facie case against him. In the mean time the present adversarial system means that much time is then lost while opinion is canvassed and evidence is sought that could justify the HM(61) 112 process.

There are bodies who regularly determine and certify the professional competence of doctors and specialists - the General Medical Council and the royal colleges and faculties. If we are to regulate our own profession then the royal colleges must be concerned in cases of alleged professional incompetence, if only to act as a preliminary screener for the GMC to determine if there is a prima facie case. The disciplinary committee of the General Medical Council is well experienced in judging the professional competence and conduct of doctors.

Written statements containing all allegations imputing a doctor's competence should be obtained within days of the original suspension and copies submitted to both the suspended doctor and the appropriate royal college or faculty, with the objective that the case should be resolved within six months. There is an old legal adage that justice deferred is justice denied. Failure to establish the date of any hearing or inquiry within six months of the original suspension should result in the automatic reinstatement of the suspended doctor. Such a system would save the NHS millions of pounds and the suspended doctor and his family much anguish. Given the virtual monopoly employer status of the NHS, the evidence justifying dismissal of a hospital doctor should be solid and unequivocal, and as such it should not take a competent administration long to gather.

Dr Roy suggested that there may be as many as 40 doctors suspended under $\mathrm{HM}(61) 112$ procedures. Defending these doctors will cost the profession over $11 \mathrm{~m}$, but the defence costs are not reimbursed even if the doctor is found innocent or the case is dropped. This is another of the injustices of the present system and one of the reasons why the subscriptions to our defence organisations are so high. If the system were streamlined and the medical profession self regulatory then the reduced defence expenditure would be tolerable, but not while we are at the mercy of a meandering bureaucratic system, a process that one eminent judge described as making legal systems look like Toytown.

Another major criticism of the pesent system is that there are virtually no checks on maladministration in disciplinary processes. The Health Service Commissioner should be able to investigate 